\title{
Analysis of Turnover Factors by Environmental Factor and Job Stress for 20-30s Hairdressers
}

\author{
Hyun-Yurl $\mathrm{Cho}^{1}$, Young-Sam Kim ${ }^{2 *}$ \\ ${ }^{1}$ Department of Cosmetics Engineering, Konkuk University, Seoul, Korea \\ ${ }^{2}$ Department of Image Industry, Graduate School of Engineering, Konkuk University, Seoul, Korea
}

\begin{abstract}
"Corresponding author: Young-Sam Kim, Department of Image Industry, Graduate School of Engineering, Konkuk University, 120 Neungdong-ro, Gwangjin-gu, Seoul 05029, Korea
\end{abstract}

Tel.: +82 24500463

Email: gracehelen@konkuk.ac.kr

\section{Received October 31, 2019}

Revised March 06, 2020

Accepted March 18, 2020

Published March 30, 2020

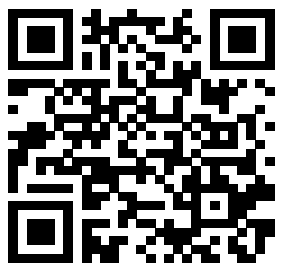

\begin{abstract}
Purpose: This study analyzes the environmental factors and job stress of hair dressers and tries to verify the job environment and the effects of stress on the turnover factors. Methods: Data were collected from hair dressers in their 20 s and 30 s, analyzed using the SPSS WIN 25.0 program, and $t$-test, one-way ANOVA, $x^{2}$ (Chisquare)-test, correlation, and multiple regression were conducted. Result: Education system, working environment, welfare, wages and job stress, which are factors of human resources management, have significant influence on the degree of turnover. Conclusion: It is hoped that the results of this research should be used as basic data for the development of the beauty industry, and that a systematic human resource management should be planned and carried out to accurately analyze job stress and environmental factors that have changed according to changes in the consciousness of hair dressers.
\end{abstract}

Keywords: Turnover in beauty industry, Changing job, Turnover intention, Human resource management, Job stress

\section{Introduction}

현재의 미용 산업은 삶의 질의 꾸준한 향상과 다른 산업구조 변화와 함께 많은 성장을 거듭해 왔고, 그에 따른 인력 수급에 도 변화가 요구되어 오고 있다(Park et al., 2013). 성장 규모와 는 다르게 전문경영인의 부재로 헤어드레서들의 직무 불만족에서 오는 높은 이직률로 인해 인력난과 복리후생 등 문제점을 가지고 있다(Kim, 2008).

미용 산업의 특성은 인적자원의 기술력을 바탕으로 서비스를 창출하는 것으로 인적자원의 관리가 매우 중요하다 할 수 있다 (Oh, 2009). 헤어드레서들의 잦은 이동은 필요 없는 인력 소모일 뿐 아니라 헤어드레서 본인의 경제적 손실과 미용 산업 경영적 측면에서 인적 손실 및 경제적 손실을 가져오는 것이다. 지금의 헤어드레서들은 오랜 시간의 업무, 불확실한 승진, 복지후생시 설, 낮은 임금, 장시간의 반복적인 작업으로 인해 정신적, 신체적 으로 많은 스트레스를 받고 있으며 이로 인한 이직이 높은 것이
곧 조직의 생산성 저하라는 결과를 가져오게 된다(Park et al., 2013).

최근 헤어드레서의 감정노동, 직무소진 등에 대한 이직 의도를 조사한 연구(Yoo et al., 2014)나 미용 전공별 관련 종사자들의 이직실태 및 이직 의도를 분석한 연구(Seo et al., 2017)가 있었 으나, 미용 환경요인들을 언급하지는 못했고, 대부분 헤어드레서 의 직무 스트레스와 이직 의도의 관계(Kwak \& Song, 2008), 헤 어드레서의 직무 만족과 이직 의도의 관계(Oh \& Im, 2011) 등을 분석한 연구들은 급변하는 현재의 미용 환경과 직무 스트레스 등 을 대변하기에는 역부족이다. 이에 본 연구는 현재 수도권 지역 헤어드레서들의 환경적 요인과 직무 스트레스가 실제 이직요인에 어떠한 영향을 미치는지 살펴보고, 헤어드레서들의 구체적인 이 직 의도를 분석하고자 한다. 따라서 본 연구는 미용업계 경영자 들의 시대적 흐름이 요구하는 헤어드레서들에 대한 인식을 변화 시키고, 나아가 그들의 이직 의도를 파악하여 이직률 감소방안을 모색함으로, 체계적이고 효과적인 인적자원관리 체계 마련에 기 
초적 자료를 제공하는 데 그 목적이 있다.

\section{Methods}

\section{1. 연구참여자 및 기간}

본 연구는 수도권에 거주하는 20-30대 헤어드레서로, 현재 미 용실에서 근무하고 있는 사람을 대상으로 설문조사를 실시하였다. 조사 기간은 2018년 12 월 10 일부터 동년 동월 30 일까지 21 일 동 안 설문조사 시 심층 면담을 병행하여 직접 설문지에 기입하는 방 식으로 조사하였으며, 총 450 부를 배부하여 417 부가 회수되었으 며, 그중 응답이 정확하지 않은 21 부를 제외한 설문지 총 396 부를 최종 분석 자료로 사용하였다.

\section{2. 측정 도구}

1) 설문지 구성

설문지는 크게 7 가지 요인으로, 인구통계학적 특성 8 문항, 근무 환경 6 문항, 복지 관련 5 문항, 임금 관련 5 문항, 직무 스트레스 11 문항, 교육시스템 7 문항, 이직실태 및 이직 의도 관련 13 문항 등 총 59 문항으로 구성하였다.

2) 자료 분석

본 연구의 수집된 자료는 SPSS WIN 25.0 프로그램을 이용하 여 분석하였으며, 근무환경 만족도와 사원 복지 만족도, 임금 만족 도, 직무 스트레스, 교육시스템 만족도의 환경요인, 그리고 이직 관련 문제에 대해 알아보기 위해 $t$-test, one-way ANOVA, 그리 고 $\chi^{2}$-test를 실시하였고, 이직 의도와의 관계, 미치는 영향을 파 악하기 위해 correlation, multiple regression을 실시하였다.

Table 1. General characteristics of research participants

\begin{tabular}{|c|c|c|c|}
\hline Classification & & Frequency & Percent (\%) \\
\hline \multirow{2}{*}{ Grade } & Male & 105 & 26.5 \\
\hline & Female & 291 & 73.5 \\
\hline \multirow{4}{*}{ Age group } & $20-24$ & 83 & 21.0 \\
\hline & $25-29$ & 112 & 28.3 \\
\hline & $30-34$ & 102 & 25.8 \\
\hline & $35-39$ & 99 & 25.0 \\
\hline \multirow{2}{*}{ Marital status } & Single & 260 & 65.7 \\
\hline & Married & 136 & 34.3 \\
\hline \multirow{5}{*}{ Monthly salary (Unit: 1,000 won) } & Less than 1,000 & 18 & 4.5 \\
\hline & Less than $1,000-2,000$ & 156 & 39.4 \\
\hline & Less than $2,000-3,000$ & 132 & 33.3 \\
\hline & Less than $3,000-4,000$ & 63 & 15.9 \\
\hline & More than 4,000 & 27 & 6.8 \\
\hline \multirow{4}{*}{ Education } & High school graduate & 162 & 40.9 \\
\hline & College student & 22 & 5.6 \\
\hline & College graduate & 188 & 47.5 \\
\hline & Graduate degree or higher & 24 & 6.1 \\
\hline \multirow{5}{*}{ Beautician career (Unit: year) } & Less than 1 & 29 & 7.3 \\
\hline & $1-3$ & 98 & 24.7 \\
\hline & $4-7$ & 93 & 23.5 \\
\hline & $8-11$ & 96 & 24.2 \\
\hline & More than 11 & 80 & 20.2 \\
\hline \multirow{5}{*}{ Career in current job } & Less than 1 & 102 & 25.8 \\
\hline & $1-3$ & 171 & 43.2 \\
\hline & $4-7$ & 76 & 19.2 \\
\hline & 8-11 & 35 & 8.8 \\
\hline & More than 11 & 12 & 3.0 \\
\hline Total & & 396 & 100.0 \\
\hline
\end{tabular}




\section{Results and Discussion}

\section{1. 연구참여자의 일반적 특성}

본 연구의 연구참여자의 일반적 특성은 Table 1 과 같으며, 총 396 명 중 성별로는 여자 헤어드레서가 $73.5 \%$ 로 남자 헤어드레 서 $26.5 \%$ 보다 높은 분포를 보였다. 연령별로는 25-29세가 $28.3 \%$ 로 가장 많았으며, 다음으로 30-34세 25.8\%, 35-39세 25.0\%, 20-24세 $21.0 \%$ 순으로 나타났다.

결혼여부별로는 미혼이 $65.7 \%$ 로 기혼 $34.3 \%$ 보다 많았다. 월 급 수준별로는 100-200만원 미만이 39.4\%로 가장 높은 분포를 보 였으며, 다음으로 200-300만원 미만 33.3\%, 300-400만원 미만
$15.9 \%, 400$ 만원 이상 $6.8 \%, 100$ 만원 미만 $4.5 \%$ 순이었다. 학력별 로는 대학교 졸업이 $47.5 \%$ 로 가장 많았으며, 고등학교 졸업 $40.9 \%$, 대학원 이상 $6.1 \%$, 대학교 재학 $5.6 \%$ 순으로 나타났다.

미용경력별로는 1-3년이 $24.7 \%$ 로 가장 많았으며, 다음으로 8-11년 24.2\%, 4-7년 23.5\%. 11년 이상 20.2\%, 1년 미만 7.3\% 순으로 나타났다. 현 직장 근무경력별로는 1-3년이 43.25로 가 장 높은 분포를 차지하였으며, 다음으로 1 년 미만 $25.8 \%, 4-7$ 년 $19.2 \%, 8-11$ 년 8.8\%, 11년 이상 $3.0 \%$ 순이었다.

\section{2. 측정 도구의 신뢰도 검증}

본 연구의 측정 도구의 신뢰도를 검증한 결과는 Table 2 와 같으며

\section{Table 2. Reliability of measurement tools}

\begin{tabular}{|c|c|c|c|c|c|c|}
\hline \multicolumn{2}{|l|}{ Classification } & \multicolumn{3}{|c|}{ Number of questions } & \multicolumn{2}{|c|}{ Cronbach's $\alpha$} \\
\hline \multirow{5}{*}{ Environmental factors } & Working environment satisfaction & \multicolumn{3}{|c|}{10} & \multicolumn{2}{|c|}{0.80} \\
\hline & Employee welfare satisfaction & \multicolumn{3}{|c|}{5} & \multicolumn{2}{|c|}{0.75} \\
\hline & Pay satisfaction & \multicolumn{3}{|c|}{5} & \multicolumn{2}{|c|}{0.66} \\
\hline & Job stress & \multicolumn{3}{|c|}{10} & \multicolumn{2}{|c|}{0.73} \\
\hline & Education system satisfaction & \multicolumn{3}{|c|}{7} & \multicolumn{2}{|c|}{0.90} \\
\hline \multicolumn{2}{|l|}{ Turnover intention } & \multicolumn{3}{|c|}{6} & \multicolumn{2}{|c|}{0.68} \\
\hline \multicolumn{2}{|l|}{ Classification } & $\mathrm{N}$ & Mean & $\mathrm{SD}$ & $t$ or $F$ & $p$ \\
\hline \multirow{2}{*}{ Grade } & Male & 105 & 2.39 & 0.56 & \multirow{2}{*}{-1.33} & \multirow{2}{*}{0.185} \\
\hline & Female & 291 & 2.48 & 0.50 & & \\
\hline \multirow{4}{*}{ Age group } & $20-24$ & 83 & 2.46 & 0.58 & \multirow{4}{*}{2.18} & \multirow{4}{*}{0.090} \\
\hline & $25-29$ & 112 & 2.55 & 0.50 & & \\
\hline & $30-34$ & 102 & 2.43 & 0.53 & & \\
\hline & $35-39$ & 99 & 2.37 & 0.47 & & \\
\hline \multirow{2}{*}{ Marital status } & Single & 260 & 2.48 & 0.53 & \multirow{2}{*}{1.40} & \multirow{2}{*}{0.162} \\
\hline & Married & 136 & 2.40 & 0.50 & & \\
\hline \multirow{3}{*}{ Monthly salary (Unit: 1,000 won) } & Less than 2,000 & 174 & 2.52 & 0.54 & \multirow{3}{*}{$5.13^{* *}$} & \multirow{3}{*}{0.006} \\
\hline & Less than $2,000-3,000$ & 132 & 2.47 & 0.50 & & \\
\hline & More than 3,000 & 90 & 2.31 & 0.47 & & \\
\hline \multirow{2}{*}{ Education } & High school graduate & 162 & 2.40 & 0.55 & & 110 \\
\hline & College student/graduate or higher & 234 & 2.49 & 0.49 & -1.50 & U. $\perp \perp Y$ \\
\hline & Less than 4 & 127 & 2.53 & 0.53 & & \\
\hline Reoutician sarear (Init. veor) & $4-7$ & 93 & 2.57 & 0.55 & $562^{* *}$ & $\cap \cap \cap 1$ \\
\hline Deauciciall career (Uill. year) & $8-10$ & 96 & 2.35 & 0.48 & 0.02 & $0.00 \perp$ \\
\hline & More than 11 & 80 & 2.33 & 0.46 & & \\
\hline & Less than 1 & 102 & 2.57 & 0.52 & & \\
\hline Coreer in ourrent inh IInit & $1-3$ & 171 & 2.48 & 0.48 & $77^{*}$ & 2 \\
\hline career in curreril jun (uill. year) & $4-7$ & 76 & 2.37 & 0.58 & 4. 11 & 0.000 \\
\hline & More than 8 & 47 & 2.26 & 0.51 & & \\
\hline Total & & 396 & 2.45 & 0.52 & & \\
\hline
\end{tabular}

${ }^{* *} p<0.01$. 
Cronbach $\alpha$ 가 근무환경 만족도 0.80 , 사원 복지 만족도 0.75 , 임금 만족도 0.66 , 직무 스트레스 0.73 , 교육시스템 만족도 0.90 , 이직 의 도 0.68 로, 모두 0.60 이상으로 나타났다. 따라서 본 연구의 측정 도 구는 신뢰할 만한 수준이다.

\section{3. 이직의도}

헤어드레서들의 이직 의도에 대해 살펴본 결과는 Table 3 과 같이 5 점 만점 중 전체 평균이 2.45 로, 헤어드레서들은 이직 의도가 낮은 것으로 나타났다. 월급수순별로는 월급수준이 낮은 헤어드레서 일 수록 이직 의도가 높았으며 월급수준에 따라 유의미하였다 $(p<0.01)$. 미용경력별로는 4-7년인 헤어드레서가 이직 의도가 가장 높았고, 11 년 이상인 헤어드레서는 다른 헤어드레서보다 이직 의도가 낮았 으며, 미용경력에 따라 유의미하였다 $(p<0.01)$. 이는 경력이 짧은 헤 어드레서들의 이직 의도가 높다는 연구(Yoo et al., 2014)와 유사한 결과로 인턴 단계의 헤어드레서는 현 직장의 환경적응과 주변 동료 들과의 관계 형성에 미흡하며, 다른 근무지로의 이직을 고민하는 이 유로 이직 의도가 높은 것으로 추정된다. 또한 헤어드레서들의 이직 의도는 현 직장 근무경력에 따라 유의미하였다 $(p<0.01)$. 이는 경력, 직위, 연령이 낮을수록 이직 의도가 높다는 연구(Yoo et al., 2014) 와 유사한 결과이다. 따라서 이직 의도에는 연령 또한 중요한 요소로 꼽힌다는 결과이기도 하다. Oh \& Im (2011)는 근속기간이 긴 헤어 드레서들은 근속기간이 짧은 헤어드레서에 비해 이직 의도가 낮다고 보고하였는데, 이 또한 경제적 안정과 근무환경의 적응, 주변 동료들 과의 친밀도 형성에 따른 영향으로 추정되어 진다.

1) 근무환경, 사원 복지, 임금 만족도와 직무 스트레스와의 관계 헤어드레서들의 근무환경 만족도, 사원 복지 만족도, 임금 만족도
와 직무 스트레스와의 관계에 대해 살펴본 결과는 Table 4에서 보는 바와 같이 근무환경 만족도 $(p<0.001)$ 와 사원 복지 만족도 $(p<0.001)$, 임금 만족도 $(p<0.001)$ 는 직무 스트레스와 통계적으로 유의미한 부적 상관관계를 보였다.

이는 Kang \& Rhee (2012)의 연구와 유사한 결과로 헤어드레서들 은 근무환경 만족도와 사원 복지 만족도, 그리고 임금 만족도가 높을 수록 직무 스트레스가 낮음을 알 수 있다. 직무 만족도를 높이며 이 직 의도를 낮추는 것에 있어 인간관계 만족과 물리적 보상은 중요한 요소이다. 또한, 환경요인이 좋을수록 직무 스트레스가 낮아진다는 연구(Chae \& Na, 2015)와도 유사하며, 본 연구의 환경요인인 인적 지원과 물적 지원이 원활할수록 직무 스트레스가 낮아진다는 결과를 도출한 것은 고무적이다.

\section{2) 환경요인이 이직 의도에 미치는 영향}

헤어드레서들의 근무환경 만족도, 사원 복지 만족도, 임금 만족 도, 직무 스트레스, 교육시스템 만족도의 환경요인이 이직 의도에 미 치는 영향에 대해 살펴본 결과는 Table 5 와 같다.

헤어드레서들의 근무환경 만족도, 사원 복지 만족도, 임금 만족 도, 직무 스트레스, 교육시스템 만족도의 환경요인이 이직 의도에 미 치는 영향을 보면, 이 모형은 적합성이 검증되었으며 $(p<0.001)$, 약 $15.5 \%\left(\mathrm{R}^{2}=0.155\right)$ 의 설명력을 지니고 있다.

헤어드레서들의 이직 의도에는 근무환경 만족도 $(p<0.001)$ 와 사 원 복지 만족도 $(p<0.01)$, 교육시스템 만족도 $(p<0.01)$ 가 통계적으로 유의미한 부(-)의 영향을 미쳤고, 직무 스트레스 $(p<0.01)$ 는 통계적 으로 유의미한 정(+)의 영향을 미쳤으며, 임금 만족도는 통계적으로 유의미한 영향을 미치지 않았다. 이는 Park et al. (2013)의 사원 복 지와 임금 불만족 시 이직 의도가 높아진다는 보고와 유사한 결과로

Table 4. Relationship between work environment, employee welfare, wage satisfaction and job stress

\begin{tabular}{lccc}
\hline Classification & Working environment satisfaction & Employee welfare satisfaction & Pay satisfaction \\
Job stress & $-0.534^{* * *}(0.000)$ & $-0.174^{* * *}(0.000)$ & $-0.309^{* * *}(0.000)$ \\
\hline${ }^{* * *} p<0.001$. & &
\end{tabular}

Table 5. Impact of environmental factors on turnover intention

\begin{tabular}{|c|c|c|c|c|}
\hline \multirow[t]{2}{*}{ Classification } & \multicolumn{4}{|c|}{ Turnover intention } \\
\hline & $\mathrm{b}$ & $\beta$ & $t$ & $p$ \\
\hline Working environment satisfaction & -0.231 & -0.252 & $-3.830^{* * *}$ & 0.000 \\
\hline Employee welfare satisfaction & -0.114 & -0.172 & $-3.082^{* *}$ & 0.002 \\
\hline Pay satisfaction & -0.012 & -0.015 & -0.258 & 0.797 \\
\hline Job stress & 0.154 & 0.147 & $2.639^{* *}$ & 0.009 \\
\hline Education system satisfaction & -0.115 & -0.169 & $-3.059^{* *}$ & 0.002 \\
\hline Constant & & & $10.040^{* * *}$ & 0.000 \\
\hline $\mathrm{R}^{2}$ & \multicolumn{4}{|c|}{0.155} \\
\hline$F(p)$ & \multicolumn{4}{|c|}{$14.305^{* * *}(0.000)$} \\
\hline
\end{tabular}

${ }^{*} p<0.01 ;{ }^{* * *} p<0.001$. 
급여 수준, 주변 동료와의 관계 만족도가 높을수록 이직 의도가 낮 아진다는 것을 알 수 있고, 양질의 교육을 받는 것 역시 중요한 것임 을 추정할 수 있다. 또한, 직무 스트레스가 높을수록 직무 만족이 낮 아지고, 직무 만족이 낮아지면 이직 의도가 높아진다는 연구(Seo \& Park, 2018)와도 유사한 결과이다.

이상과 같이 헤어드레서들은 근무환경 만족도와 사원 복지 만족 도, 그리고 교육시스템 만족도가 높을수록 이직 의도가 낮으며, 직무 스트레스가 높을수록 이직 의도가 높음을 알 수 있다.

\section{Conclusion}

본 연구는 헤어드레서들의 환경요인과 직무 스트레스를 분석하고 직무 환경과 스트레스가 이직요인에 미치는 영향을 검증하여 미용 경영자들의 인식변화를 통해 효과적인 인사체계와 인적자원관리 체 계에 기초 자료를 제공하는데 그 목적을 두고 있다. 수도권에 거주하 는 20-30대 헤어드레서들 중 현재 미용실에서 근무하고 있는 사람 을 대상으로 자료를 수집하였고, 수집된 자료는 SPSS WIN 25.0 프 로그램을 이용하여 분석하였으며, $t$-test와 one-way ANOVA, $\chi^{2}-$ test를 실시한 후, correlation, multiple regression을 이용하여 추가 로 분석하여 다음과 같은 결과를 얻었다.

첫째, 헤어드레서들의 근무환경 만족도는 5 점 만점 중 전체 평균 이 3.55로 비교적 높은 것으로 나타났으며, 연령별로는 35-39세인 헤어드레서 만족도가 가장 높았으며 1 인 가구인 헤어드레서가 근무 환경 만족도가 높은 것으로 나타났다.

둘째, 직무 스트레스가 5 점 만점 중 전체 평균이 2.53 으로 그다지 높지 않은 것으로 나타났다. 월급 수준별로는 월급 수준이 낮은 헤어 드레서일수록 직무 스트레스가 높았으며, 현 직장 근무경력이 적은 헤어드레서일수록 직무 스트레스가 높은 것으로 나타났다.

셋째, 교육시스템 만족도가 5점 만점 중 전체 평균이 3.25 로 그다 지 높지 않은 것으로 나타났다. 현 직장 근무경력별로는 8년 이상인 헤어드레서가 교육시스템 만족도가 가장 높았고, 1-3년인 헤어드레 서는 다른 헤어드레서보다 교육시스템 만족도가 낮은 것으로 나타났 다.

넷째, 헤어드레서들의 이직 의도는 5 점 만점 중 전체 평균이 2.45 로 낮은 것으로 나타났다. 월급수준이 낮은 헤어드레서일수록 이직 의도가 높았으며, 미용경력별로는 4-7년인 헤어드레서가 이직 의도 가 가장 높았고, 11 년 이상인 헤어드레서는 다른 헤어드레서보다 이 직 의도가 낮았으며, 현 직장 근무경력이 적은 헤어드레서일수록 이 직 의도가 높은 것으로 나타났다.

다섯째, 헤어드레서들의 근무환경 만족도, 사원 복지 만족도, 임 금 만족도가 직무 스트레스에 미치는 영향에 대해 살펴본 결과 헤어 드레서들의 직무 스트레스에는 근무환경 만족도 $(p<0.001)$ 가 통계적 으로 유의미한 부(-)의 영향을 미쳤으며, 사원 복지 만족도와 임금
만족도는 통계적으로 유의미한 영향을 미치지 않았다. 따라서 헤어 드레서들은 근무환경 만족도가 높을수록 직무 스트레스가 낮은 것으 로 나타났다.

여섯째, 헤어드레서들의 근무환경 만족도, 사원 복지 만족도, 임 금 만족도와 교육시스템 만족도와의 관계에 대해 살펴본 결과는 근 무환경 만족도 $(p<0.001)$ 와 사원 복지 만족도 $(p<0.001)$, 임금 만족도 $(p<0.001)$ 는 교육시스템 만족도와 통계적으로 유의미한 정적 상관관 계를 보였다. 따라서 헤어드레서들은 근무환경 만족도와 사원 복지 만족도, 그리고 임금 만족도가 높을수록 교육시스템 만족도가 높은 것으로 나타났다.

일곱째, 헤어드레서들의 근무환경 만족도, 사원 복지 만족도, 임 금 만족도, 직무 스트레스, 교육시스템 만족도의 환경요인이 이직 의도에 미치는 영향에 대해 살펴본 결과는 이직 의도에는 근무환경 만족도 $(p<0.001)$ 와 사원 복지 만족도 $(p<0.01)$, 교육시스템 만족도 $(p<0.01)$ 가 통계적으로 유의미한 부(-)의 영향을 미쳤고, 직무 스트 레스 $(p<0.01)$ 는 통계적으로 유의미한 정 $(+)$ 의 영향을 미쳤다. 따라 서 헤어드레서들은 근무환경 만족도와 사원 복지 만족도, 그리고 교 육시스템 만족도가 높을수록 이직 의도가 낮으며, 직무 스트레스가 높을수록 이직 의도가 높은 것으로 나타났다.

본 연구를 통하여 헤어드레서들의 이직개선을 위한 본 연구의 이 직요인에 미치는 영향을 검증한 결과를 토대로 다음과 같은 제언을 한다.

첫째, 임금관련 개선이 필요하다. 이직 고민이 있는 헤어드레서들 은 가장 큰 영향으로 임금 관련 문제를 선택하였다. 이는 임금 만족 이 조직의 성과를 결정하는 조직 구성원의 직무 행동에 영향을 주고, 조직 구성원의 발전과 직무의 질 향상을 가져온다는 연구(Locke, 1976)와도 유사한 결과로 경제적 여유가 동반될 때 직무 만족으로 연결되어 이직 의도 낮아지는 것으로 추정할 수 있다. 그러므로 임금 관련에 대한 전반적인 개선이 이행된다면 헤어드레서들의 이직 고민 을 해결하는 가장 적극적인 방안이 될 것이다.

둘째, 사원 복지 관련한 개선이 필요하다. 헤어드레서들은 4 대 보 험 및 퇴직금에 관련하여 만족도가 낮은 것으로 나타났다. Choi \& Lee (2004)는 퇴직금제도 확립과 4대 보험 가입을 하는 것은 단기적 으로 보게 될 시 지출의 증가로 수익감소로 볼 수 있으나 조직 구성 원의 이직률을 낮추어 수익 창출이라는 조직의 근본 목적을 달성할 수 있을 것이라 하였다. 이렇게 직업과 조직의 신뢰도를 가질 수 있 게 하는 것은 조직 구성원의 이직 고민이나 이직 의도 개선에 도움이 될 수 있는 것이다.

셋째, 체계적 교육시스템이 필요하다. 이직 고민 중 교육시스템 만족 정도가 이직 의도에 영향을 미치는 것으로 나타났다. 현 직장 근무경력별로 1-3년인 기술 습득이 가장 필요한 인턴과 초급 헤어 드레서들의 교육시스템 만족도가 낮은 것으로 나타났다. Lee et al., (2011)은 교육훈련과 이직 의도는 통계적으로 유의하지 않은 결과로 교육훈련성과가 이직 의도에는 직접적인 영향을 미치지 않는다고 하 
였다. 그러나 시대의 변화와 고학력 헤어드레서들의 배출로 인해 이 전보다 더 양질의 교육과 체계적인 교육시스템을 원하는 헤어드레서 가 늘어난 것으로 나타났으므로 이들의 교육시스템 만족도를 향상시 키는 것 또한 결과적으로 이직 고민을 해결할 수 있는 방안이 될 것이 다.

본 연구는 연구참여자 선정에 있어 수도권 지역을 대상으로 하여, 연구결과를 모든 헤어드레서들 에게 일반화하기에는 다소 부족함이 있었으나, 시대의 변화에 따른 고학력자의 배출은 지역과 직종, 숙련 도 등을 망라하여 나타나는 현상이므로(Park \& Lee, 2014), 헤어드 레서들의 의식변화에 따라 바뀐 직무 스트레스, 환경요인을 이직요 인으로 분석한 본 연구가 그들의 이직 의도를 낮추는 기초 자료로 활 용되어 조직 경영자들에게 효과적인 인적자원관리에 도움이 되기를 기대한다.

This work is part of the Hyun-Yurl Cho's M.Sc.thesis at the Konkuk University, Seoul, Korea.

\section{Author's contribution}

HYC designed, performed experiments, analyzed data, and wrote the manuscriptYSK supervised the project. All figures are created by the author and the co-authors. All authors read and approved the final manuscript.

\section{Author details}

Hyun-Yurl Cho (Graduate student), Department of Cosmetics Engineering, Konkuk University, 120 Neungdong-ro, Gwangjingu, Seoul 05029, Korea; Young-Sam Kim (Professor), Department of Image Industry, Graduate School of Engineering, Konkuk University, 120 Neungdong-ro, Gwangjin-gu, Seoul 05029, Korea.

\section{References}

Chae HO, Na MS. A study of effects of internal marketing and job satisfaction on turnover intention in hair beauty salon employees. Journal of The Korean Society of Beauty and Arts, 16: 171-187, 2015.

Choi SY, Lee HJ. The study of beauty industry parts' current social insurance status and its analysis. Journal of Korea Safety Management \& Science, 15: 393-399, 2013.

Kim HH. Analysis of relationship between job performance and emotional labor of hotel employee. Journal of Culture
Tourism, 29: 127-144, 2008.

Kang JA, Rhee YJ. A study on the relationships among emotional labor, job satisfaction and turnover intention of beauty industry professionals. The Research Journal of Costume Culture, 20: 664-678, 2012.

Kwak KS, Song YS. The factors of job satisfaction, degree of occupational satisfaction and turnover intention according to characterization of hair beauty service workers. Journal of the Korean society of beauty cultural arts, 3: 68-83, 2014.

Lee EY, Hwang JH, Lee SB. A study of the effects of training factors on transfer, self-efficacy and job performance. International Journal of Tourism Management and Sciences, 25: 275-294, 2011.

Locke EA. The nature and causes of job satisfaction. In: Handbook of industrial and organizational psychology (1st ed.). Dunnette MD (ed.), Rand McNally, Chicago, pp12971349, 1976.

Oh KH. The effect of beauty salon staffs' organizational conflict on organizational commitment and turnover intention. Asian Journal of Beauty and Cosmetology, 7: 367-383, 2009.

Oh R, Im EJ. The effect of the job satisfaction factors of hair designers on turnover intention. Journal of Investigative Cosmetology, 7: 29-36, 2011.

Park YJ, Han EH, Leem JS, Han CJ. A study on the effects of the beauty industry work's occupational stress, job satisfaction and emotional labor on turnover intention. Asian Journal of Beauty and Cosmetology, 11: 111-118, 2013.

Park YJ, Lee HY. Differential wage effects of over-education among four distinct occupational classes and regional comparison. Journal of Korea Planning Association, 49: 255-276. 2014.

Seo HS, Kang SG, Kim JH. A study on motivation for changing Jobs among beauty industry professionals. Journal of the Korean Society of Design Culture, 23: 505-517, 2017.

Seo SS, Park CH. Effects of emotional labor for aestheticians on job stress, satisfaction, and turnover. Asian Journal of Beauty and Cosmetology, 16: 333-345, 2018.

Yoo EJ, shim SN, Kim SK. The effect of the beauty salon worker's emotional labor, job stress, job burnout and social support on turnover intention. Journal of Digital Convergence, 12: 427-439, 2014. 


\section{국문초록}

\section{0-30대 헤어드레서의 환경요인과 직무 스트레스로 인한 이직요인 분석}

조현열 ${ }^{1}$, 김영삼 ${ }^{2 *}$

${ }^{1}$ 건국대학교 화장품공학과, 서울, 한국

${ }^{2}$ 건국대학교 산업대학원 이미지산업학과, 서울, 한국

목적: 본 연구는 헤어드레서들의 환경요인과 직무 스트레스를 분석하고 직무 환경과 스트레스가 이직요인에 미치는 영향을 검증 하고자 한다. 방법: 20-30대 헤어드레서들을 대상으로 자료를 수집하였고, SPSS WIN 25.0 프로그램을 이용하여 분석하였으며, $t$-test, one-way ANOVA, $\chi^{2}$ (Chi-square)-Test, Correlation, Multiple Regression을 실시하였다. 결과: 인적자원관리 요인인 교 육시스템, 근무환경, 복지, 임금, 직무 스트레스가 이직의도에 유의미한 영향을 미치는 것으로 나타났다. 결론: 본 연구결과가 미용 산업의 발전을 위하는 기초자료로 활용되기를 바라며, 헤어드레서들의 의식변화에 따라 바뀐 직무 스트레스, 환경요인을 정확히 분 석하여 이직 의도를 낮추는 쳬계적인 인적자원관리를 계획하고 진행하여야 할 것으로 생각되어 진다.

핵심어: 미용이직, 이직, 이직 의도, 인적자원관리, 직무 스트레스

\section{참고문헌}

강주아, 이영주. 미용서비스업 종사자의 감정노동과 직무만족 및 이직의도의 관계분석. 복식문화연구, $20: 664-678$, 2012.

곽기숙, 송연숙. 헤어 미용서비스업 종사자들의 특성에 따른 직무만족 요인, 직업만족 정도 및 이직의도. 대한미용문화예 술학회지, 3: 68-83, 2014.

김헌형. 호텔 종사원의 감정노동과 직무성과(조직몰입, 직무만족, 이직의도)의 상간관계 분석. 여행학연구, $29: 127-144$, 2008.

박유정, 한은희, 임진숙, 한채정. 직무스트레스, 직무만족도, 감정노동이 미용종사자의 이직의도에 미치는 영향연구. 아시 안뷰티화장품학술지, 11: 111-118, 2013 .

박유진, 이화연. 직종특성별 과잉학력에 따른 임금효과 및 지역 간 비교. 국토계획, 49: 255-276, 2014

서상숙, 박철호. 피부미용사의 감정노동이 직무스트레스, 직무만족, 이직의도에 미치는 영향. 아시안뷰티화장품학술지, 16: $333-345,2018$.

서현숙, 강성구, 김지현. 뷰티산업종사자의 이직 동기에 관한 분석. 한국디자인문화학회지, 23: 505-517, 2017.

오경헌. 미용실 종사자의 조직갈등이 조직몰입과 이직의도에 미치는 영향. 아시안뷰티화장품학술지, $7: 367-383,2009$.

오량, 임은진. 미용사의 직무만족 요인이 이직의도에 미치는 영향. 대한미용학회지, 7: 29-36, 2011.

유은주, 심선녀, 김순구. 미용실 종사자의 감정노동, 직무스트레스, 직무소진 및 사회적 지지가 의직의도에 미치는 영향. 디지털융복합연구, 12: 427-4.39, 2014.

이은용, 황정현, 이수범. 교육훈련요인에 따른 교육훈련 전이, 자기효능감 및 직무성과에 미치는 영향에 관한 연구. 관광연 구, 25: 275-294, 2011 .

채희옥, 나명석. 헤어미용 종사자의 내부마케팅과 직무만족이 이직의도에 미치는 영향. 한국인체미용예술학회지, 16 : 171-187, 2015.

최서연, 이현진. 미용업 분야의 사회보험 가입 실태 및 분석에 관한 연구: 헤어, 네일, 피부, 메이크업 분야를 중심으로. 대 한안전경영과학회지, 15: 393-399, 2013. 


\section{中文摘要}

\section{0-30岁理发师离职因素的环境因素与工作压力分析}

趙現烈 ${ }^{1}$, 金永三 $^{2 \star}$

建国大学化妆品工学科, 首尔, 韩国

2建国大学产业大学院影像产业学科, 首尔, 韩国

目的: 通过对理发师的环境因素和工作压力的分析, 验证工作环境和压力对离职因素的影响。方法: 采用SPSS WIN 25.0统计软件对20、30岁的美发师进行统计分析, 采用t检验、单因素方差分析、卡方检验、相关分析和多 元回归分析。结果: 教育制度、工作环境、福利、工资、工作压力等因素对离职率有显著影响。结论: 希望本研 究成果能作为美容行业发展的基础数据, 规划和实施系统的人力资源管理, 根据美发师意识的变化, 准确分析 工作压力和环境因素的变化。

关键词: 美容行业的离职，离职，离职意向，人力资源管理，工作压力 